\title{
Is there an impact of public smoking bans on self-reported smoking status and exposure to secondhand smoke?
}

\author{
Alisa B Naiman ${ }^{1,2,3^{*}}$, Richard H Glazier ${ }^{1,2,4}$, Rahim Moineddin ${ }^{1,2,5}$
}

\begin{abstract}
Background: Implementation of smoke free policies has potentially substantial effects on health by reducing secondhand smoke exposure. However little is known about whether the introduction of anti-smoking legislation translates into decreased secondhand smoke exposure. We examined whether smoking bans impact rates of secondhand smoke exposure in public places and rates of complete workplace smoking restriction.

Methods: Canadian Community Health Survey was used to obtain secondhand smoking exposure rates in 15 Ontario municipalities. Data analysis included descriptive summaries and 95\% confidence intervals were calculated and compared across groups

Results: Across all studied municipalities, secondhand smoke exposure in public places decreased by $4.7 \%$ and workplace exposure decreased by $2.3 \%$ between the 2003 and 2005 survey years. The only jurisdiction to implement a full ban from no previous ban was also the only setting that experienced significant decreases in both individual exposure to secondhand smoke in a public place $(-17.3 \%, 95 \% \mathrm{Cl}-22.8,-11.8)$ and workplace exposure $(-18.1 \%, 95 \% \mathrm{Cl}-24.9,-11.3)$. Exposures in vehicles and homes declined in almost all settings over time.

Conclusions: Implementation of a full smoking ban was associated with the largest decreases in secondhand smoke exposure while partial bans and changes in existing bans had inconsistent effects. In addition to decreasing exposure in public places as would be expected from legislation, bans may have additional benefits by decreasing rates of current smokers and decreasing exposures to secondhand smoke in private settings.
\end{abstract}

\section{Background}

Tobacco use is the leading cause of preventable disease and death worldwide. Secondhand smoke (SHS) is defined as an involuntary exposure to a combination of diluted cigarette side stream smoke and the exhaled smoke from smokers [1]. In the United States, SHS causes over 46,000 deaths due to heart disease and 200,000 episodes of childhood asthma per year [2]. Public health campaigns have been designed to increase awareness of the dangers of SHS and many jurisdictions have enacted legislation to restrict smoking [3].

However, little is known about whether the introduction of anti-smoking legislation translates into decreased SHS exposure. There is also limited information on the

\footnotetext{
* Correspondence: a.naiman@utoronto.ca

${ }^{1}$ Primary Care and Population Health, Institute for Clinical and Evaluative

Studies, (2075 Bayview Avenue Room G1-06), Toronto, (M4N 3M5), Canada Full list of author information is available at the end of the article
}

degree to which smoking bans discourage smoking and thereby result in lower smoking rates. Fong et al (2006) evaluated the behavioural impact of the introduction of a smoke-free law in a cohort survey in Ireland in 2004. The introduction of the law led to declines in all venues including workplaces, restaurants and bars [4]. In this study, the relationship between smoking bans and selfreported smoking status and exposure to SHS is examined. Our main objective was to determine whether smoking bans and the type of smoking ban implemented directly impact the prevalence of SHS exposure in public places and the prevalence of complete workplace smoking restriction. Secondary objectives included determining whether smoking bans influence the number of current smokers and if they shift smoking from public places towards private settings.
C Biomed Central 


\section{Methods}

Ontario's population of 12.9 million makes it the most populous Canadian province, accounting for almost $40 \%$ of the national population [5]. The 15 largest municipalities based on the 2006 Canadian Census represent 78\% of the Ontario population and were chosen for study (Figure 1) [6].

In Ontario, smoke-free legislation was a municipal responsibility until the implementation of a provincewide smoking ban in May 2006. Each of the municipalities selected introduced smoke-free legislation from 1994 to 2004. A record of the introduction of municipal smoking bans for the 15 municipalities selected was created. Bans were classified as either partial or full. A ban was considered to be full if all public spaces were smoke-free. A ban was classified as partial if there was any exemption to the ban [7]. Figure 2 displays a historical record of the implementation of bans for the 15 Ontario municipalities selected from 1996 to 2006 .
Municipalities within Ontario are structured in different ways [8]. This structure made it difficult in some locations to select one ban for an entire area, as different smoking bans could exist within the larger geographic area. In jurisdictions in which multiple bans existed, the introduction of the smoking ban for the area with the largest population was considered the start of the ban for the entire region.

The Canadian Community Health Survey (CCHS) is a cross-sectional survey conducted by Statistics Canada that collects information related to health status, health care utilization and health determinants of Canadians aged 12 years and older [9]. The survey is based on a sample of 65,000 respondents. The 2003 (2.1) and 2005 (3.1) public access CCHS were used and responses to questions about self-reported smoking prevalence and exposure to SHS were identified for the 15 municipalities. The 2.1 and 3.1 surveys were conducted through telephone interviews and ran between January and December of 2003 and 2005 respectively [10]. The

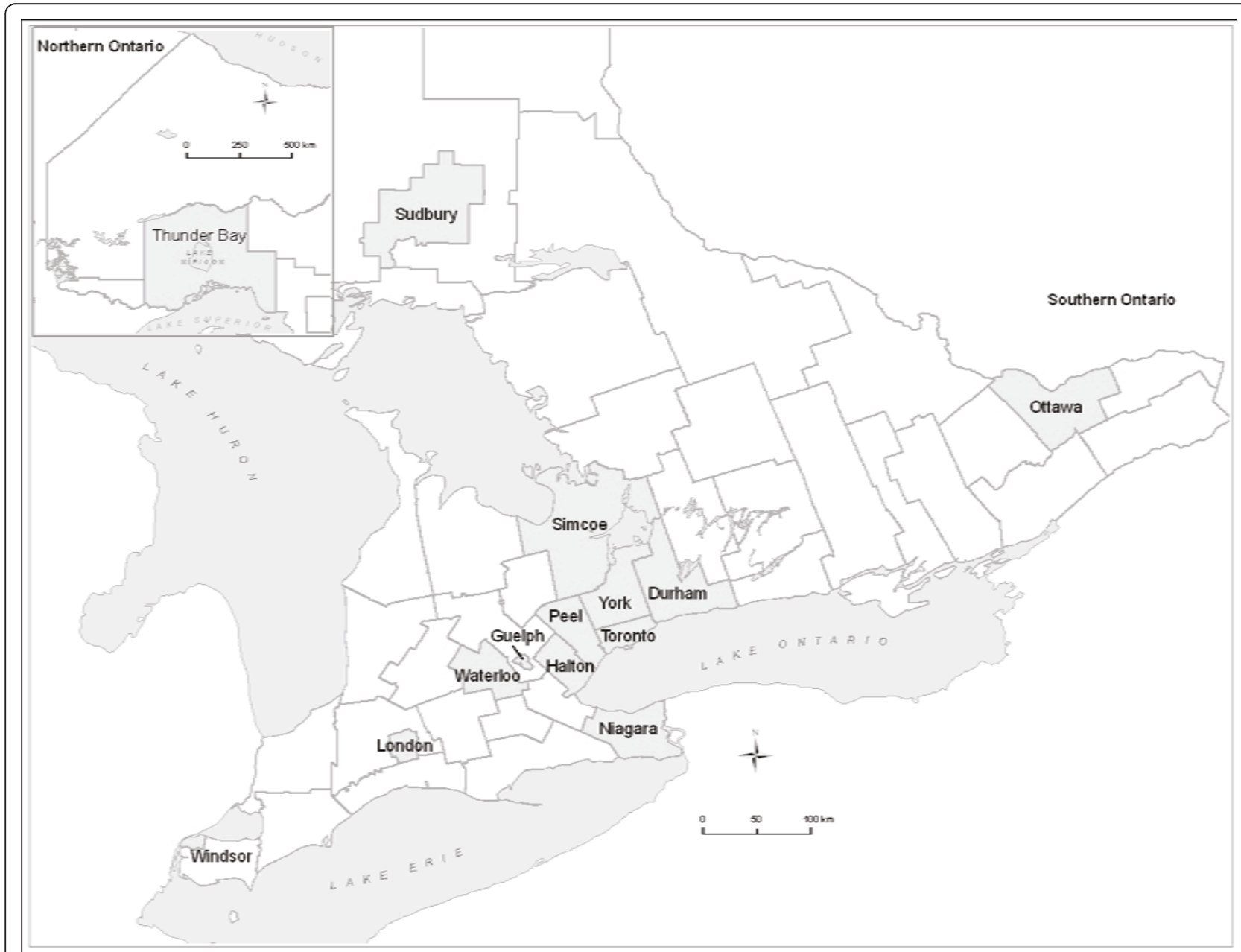

Figure 1 Map of 15 Selected Ontario Municipalities. 


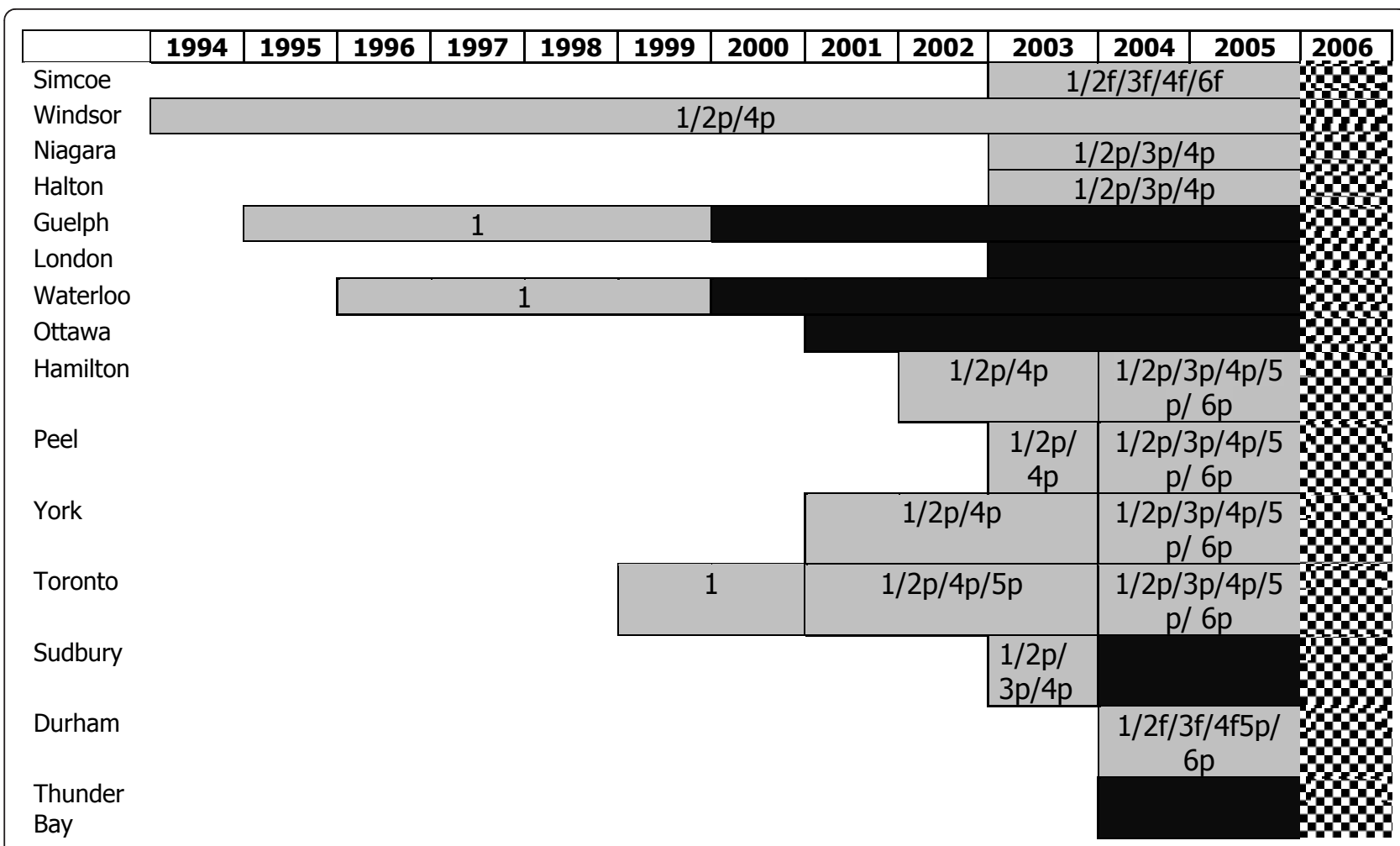

Figure 2 Historical Record of Smoking Ban Legislation by Municipality, Ontario, 1994-2006. Legend available in Table 1.

information was captured at the level of the public health unit, as this level most closely resembles the geographic representation of municipalities. Five questions pertaining to smoking status were available in the 2.1 and $3.1 \mathrm{CCHS}$ public access file [11]. These included questions about complete smoking restriction at home and at work; exposure to SHS at home, in public places, and in vehicles; and current and daily smoking. Additional file 1 includes survey questions that pertain to smoking. The 2006 Canada census was used for population composition and denominators.

This study employed a repeated cross-sectional design. Absolute and relative prevalence differences were calculated for questions on SHS exposure in public places and prevalence of complete workplace smoking restriction. To determine whether significant differences occurred for these two variables, 95\% confidence intervals were calculated and compared across groups using the test statistic proposed by Carriere et al. This method is a nonparametric estimation and hypothesis-testing procedure for standardized rates of events. This test is applicable to both binary and non-binary events and recurrent or non-recurrent events. This procedure does not require any unrealistic or non-confirmable assumptions, such as a parametric distribution or an identical distribution for all observations. The variances are

Table 1 Figure 2 legend

\begin{tabular}{|c|c|c|c|}
\hline Symbol & Location of smoking restriction & Symbol & Explanation of ban type \\
\hline 1 & Public places and workplace ${ }^{*}$ & grey square & Partial ban \\
\hline 2 & Restaurants & black square & Full ban \\
\hline 3 & Bars and billiard halls & Cross hatch square & Introduction of provincial smoking ban May 31/2006 \\
\hline 4 & Bowling alleys & & \\
\hline 5 & Bingo halls & & \\
\hline 6 & Racetracks, casinos, slots & & \\
\hline $\mathbf{P}$ & Partial ban in location, exemptions allowed (DSR permitted) & & \\
\hline $\mathbf{F}$ & Full ban, no exemptions (DSR not permitted) & & \\
\hline \multicolumn{4}{|c|}{$\begin{array}{l}\text { * "Public places" specifically excludes the locations specified as separate categories (numbers 2-6). If a municipality introduced a full smoking ban } \\
\text { in public places including restaurants and bars it would be coded as 1F,2F,3F. A municipality with a full smoking ban in public places and a }\end{array}$} \\
\hline
\end{tabular}


obtained using a simple measure of dispersion that applies to any type of event with no specific assumption as to the distribution; this measure is shown to be the usual estimator when the distribution is binomial, negative binomial, or normal [12]. Absolute prevalence differences between survey years were also calculated for the prevalence of SHS exposure at home and in vehicles, complete smoking restriction at home, and current number of smokers. Ethics approval was not required as public access files of the survey were used and no individual level information was available.

\section{Results}

Table 2 describes the demographic information about the municipalities. The gender and age structure of these populations are similar.

Figure 3 shows the self-reported rates of exposure to SHS in a public place and complete workplace restriction rates for the 15 municipalities and Ontario from the 2003 and 2005 surveys. Overall, in 2005, 10.4-19.7\% of the population reported SHS exposure in public places (13.0\% for Ontario). This was a significant decrease $(\mathrm{p}<0.0001)$ from the 2003 prevalence where $11.6-27.7 \%$ of the population reported being exposed in public (17.7\% for Ontario). In 2005, 56.7-76.6\% of respondents reported a complete smoking restriction at work (67.5\% for Ontario). This was statistically significant $(\mathrm{p}=0.0002)$ compared to 2003 percentages. Cities with the lowest SHS exposure in public places in 2005 were Waterloo, Thunder Bay, and Sudbury, all of which had full smoking bans.

Figure 3 also shows that areas in which anti-smoking legislation was introduced between the two survey years experienced the largest changes.

Thunder Bay, the only jurisdiction to implement a full ban from no previous ban between the 2003 and 2005 survey years, experienced a significant decrease in individual exposure to SHS in a public place of $-17.3 \%(95 \%$ CI -22.8, -11.8, $\mathrm{p}<0.0001)$. Durham Region, the only region that went from no ban to a partial ban also experienced a significant decline in SHS exposure of $-9.2 \%$ (95\% CI $-13.0,-5.4, \mathrm{p}<0.0001)$. Of the four municipalities in which a change in partial bans occurred between survey years, two (Toronto ( $\mathrm{p}<$ 0.0001) and Hamilton ( $\mathrm{p}=0.0052)$ ) experienced a significant decline in SHS exposure (Figure 4).

Figure 3 provides a graphical representation of the corollary to SHS complete workplace restriction - the ability to smoke at work or SHS exposure. Thunder Bay at $-18.1 \%(95 \%$ CI $-24.9,-11.3, \mathrm{p}<0.0001)$ and Waterloo at $-7.6 \%(95 \% \mathrm{CI}-13.5,-1.7, \mathrm{p}=0.0117)$ were the only two areas to experience a significant decrease in

Table 2 Demographic Characteristics of Municipalities in Relation to Smoking Bans Between 2003 and $2005^{*}$

\begin{tabular}{|c|c|c|c|}
\hline Area & $\begin{array}{c}2006 \\
\text { population }\end{array}$ & $\begin{array}{c}\text { Population } \\
<\text { age } 20 \\
(\%)\end{array}$ & $\begin{array}{c}\text { Population } \\
>\text { age } 65 \\
(\%)\end{array}$ \\
\hline \multicolumn{4}{|c|}{ No Change to Existing Partial Ban } \\
\hline Simcoe & 422,204 & 26.2 & 13.9 \\
\hline Windsor & 323,342 & 25.8 & 13.0 \\
\hline Niagara & 427,421 & 23.7 & 14.7 \\
\hline Halton & 439,256 & 26.7 & 12.5 \\
\hline \multicolumn{4}{|c|}{ No Change to Existing Full Ban } \\
\hline London & 457,720 & 24.7 & 13.8 \\
\hline Guelph & 127,009 & 25.2 & 12.4 \\
\hline Waterloo & 478,121 & 20.9 & 11.6 \\
\hline Ottawa & 812,129 & 24.3 & 12.4 \\
\hline \multicolumn{4}{|c|}{ Strengthening of Existing Partial Ban } \\
\hline Hamilton & 504,459 & 24.7 & 11.7 \\
\hline Peel Region & $1,159,405$ & 28.4 & 9.0 \\
\hline York Region & 892,712 & 27.5 & 10.2 \\
\hline Toronto & $2,503,281$ & 22.2 & 14.1 \\
\hline \multicolumn{4}{|c|}{ Introduction of Full Ban from Previous Partial Ban } \\
\hline Sudbury & 21,392 & 22.8 & 15.8 \\
\hline \multicolumn{4}{|c|}{ Introduction of Partial Ban from No Previous Ban } \\
\hline Durham Region & 561,258 & 28.3 & 10.7 \\
\hline \multicolumn{4}{|c|}{ Introduction of Full Ban from No Previous Ban } \\
\hline Thunder Bay & 149,063 & 23.7 & 15.2 \\
\hline Ontario & $12,160,282$ & 25.0 & 13.6 \\
\hline
\end{tabular}

*Values are from the 2006 Canadian Census, Statistics Canada unless otherwise noted 8. 


\section{Exposure to Second Hand Smoke in Public Places \& Ability to Smoke at Work}

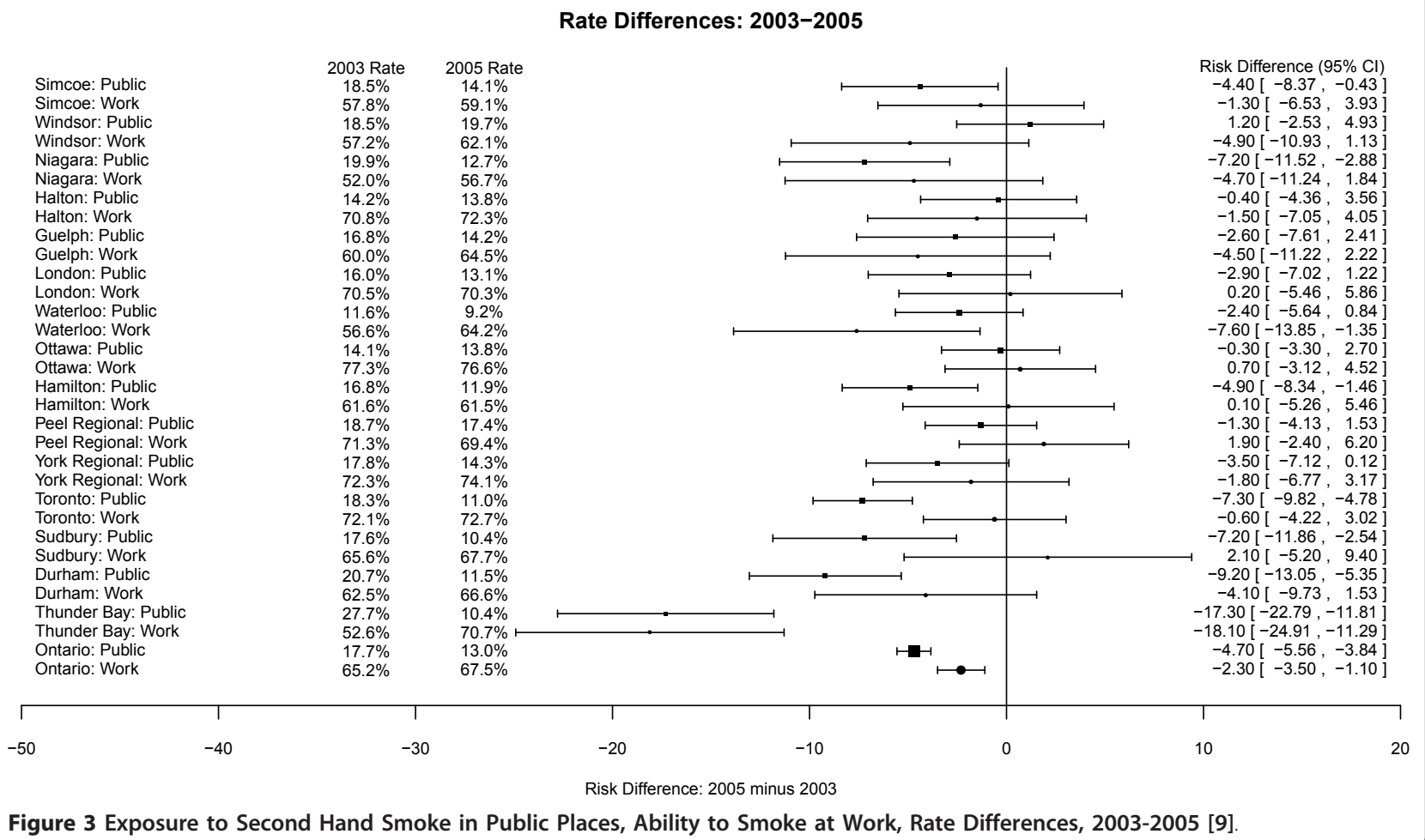

workers' ability to smoke between the 2003 and 2005 surveys. No area attained $100 \%$ smoke-free work environments despite all fifteen municipalities introducing smoke-free legislation prior to the 2005 survey.

Figure 5 shows a pooled analysis of SHS exposure and workplace restriction by the type of ban modification introduced. Municipalities that implemented any ban from no previous restrictions had larger changes in prevalence of exposure in public places and work environments then municipalities that strengthened existing legislation.

The secondary impact of anti smoking legislation can be determined by assessing whether the introduction of bans in public and workplaces leads people to shift the location of their smoking to private places. Overall, less than $15 \%$ of respondents in each area reported being exposed to SHS in vehicles and at home in the two survey years. Only Thunder Bay and Halton had small non -significant increases $(p>0.14)$ in both exposures to SHS in a vehicle and at home. Respondents in nine municipalities reported decreased exposure to SHS in vehicles between the two survey years. In addition, respondents in all municipalities reported an increase in prevalence of home smoke restriction of 2 to 10 between the two survey years, (Results not shown)

Figure 4 displays the rates of current daily smokers.
Overall, smoking prevalence ranged from 16.0 to $26.6 \%$ across the 15 municipalities in the 2005 survey (20.7\% for Ontario). Rates of self-identified current or occasional smokers decreased by up to $4 \%$ across municipalities from the 2003 to 2005 surveys. Sudbury, Durham, and Thunder Bay, the last three municipalities to introduce anti-smoking legislation had the highest percentage of smokers in 2003.

\section{Discussion}

Study results suggest that anti-smoking legislation appears to play an important role in decreasing SHS exposure. Overall, smoking bans appear most effective in decreasing exposure to SHS in public places. They also appear to increase the prevalence of complete smoking restrictions at work. But they appear to have additional benefits by decreasing the percentage of current smokers and decreasing exposures to SHS in private settings (cars and homes). Overall, municipalities with full smoking bans had lower reported SHS exposure in public places and a greater prevalence of complete smoking restriction at work than in areas with partial bans. SHS exposure is related to the level of restrictions municipalities place on banning smoking in different locations. Our results are consistent with other cross-sectional surveys conducted before and after the 


\section{Exposure to Second Hand Smoke in Public Places Ability to Smoke at Work 2003-2005}

\section{LOCATION 20032005 Rate dfference ( $96 \% \mathrm{Cl}$ )}
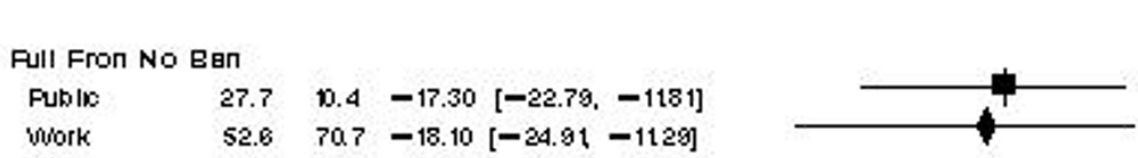

Per From No Een

$\begin{array}{llll}\text { Fuble } & 20.7 & 11.5 & -9.20[-13.01,-5.38] \\ \text { Work } & 62.5 & 60.6 & -4.0[-9.73,153]\end{array}$

Full From Per

Fubic $\left.\quad \begin{array}{lll}17.8 & 0.4 & -7.20[-1186,-2.54\end{array}\right]$

work $\quad 65.8 \quad 67.7-2.0[-9.49,5.29]$

$\begin{array}{llll}\text { Strengthening Per } & & \\ \text { Fubis } & 17.9 & 13.7 & -4.30[-5.87,-263] \\ \text { Work } & 69.3 & 69.4 & -0.01[-2.48,2.28]\end{array}$

No Change Full

$\begin{array}{lllll}\text { Fubic } & 14.8 & \text { te.6 } & -2.05\left[\begin{array}{lll}-4.02 & -0.08\end{array}\right] \\ \text { Whork } & 68.1 & 68.9 & -2.80\left[\begin{array}{ll}-5.65 & 0.05\end{array}\right]\end{array}$

No Change Par

Fubic $\quad 17.8 \quad 5.1 \quad-2.70[-4.75-0.65]$

work $\quad 59.4 \quad 625-3.10[-6.15,-0.05]$

Onterio

Fuble

work

$\begin{array}{lll}17.7 & 13.0 & -4.70[-5.56,-384] \\ 65.2 & 67.5 & -2.30[-3.50,-110]\end{array}$

]

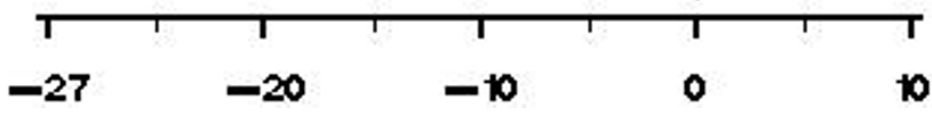

Figure 4 Pooled Analysis by Type of Ban Modification. Ban Type Full Ban from No Ban: Thunder Bay. Partial Ban From No Ban: Durham Region. Full Ban from Partial: Sudbury. Strengthening of Partial Ban: Hamilton, Peel Region, York Region, Toronto. No Change to Existing Full Ban: London, Guelph, Waterloo, Ottawa. No Change to Existing Partial Ban: Simcoe, Windsor, Niagara, Halton.

implementation of smoking bans. Two cross-sectional studies conducted in Scotland before and after the introduction of a statewide smoking ban are in agreement with our results even though they measured salivary continine [4], [13], [14]).

Approximately one-third of respondents in 2005 still reported smoking exposure at home. This number is higher than percentages of people exposed in the European Union and the United States [15], [16]. Studies have also shown that smoking employees are also affected by these bans by decreasing cigarette consumption, increasing smokers' desire to stop. Our results are consistent with a systematic review in which smoke-free workplaces were associated with a decrease in smoking prevalence of $4 \%$ [17].

The prevalence of current smokers is similar to that reported in other jurisdictions [15], [16], [18]. This study highlights that SHS is still occurring in environments legislated to be smoke-free. By 2005, 20\% of the population was still exposed to SHS in public settings, and approximately $25 \%$ of workers were still exposed to smoking at work.

It is a concern that anti-smoking legislation could shift smoking exposure from public to private places such as in vehicles as smokers have fewer locations in which they can smoke [19]. Shifting smoking to private settings 


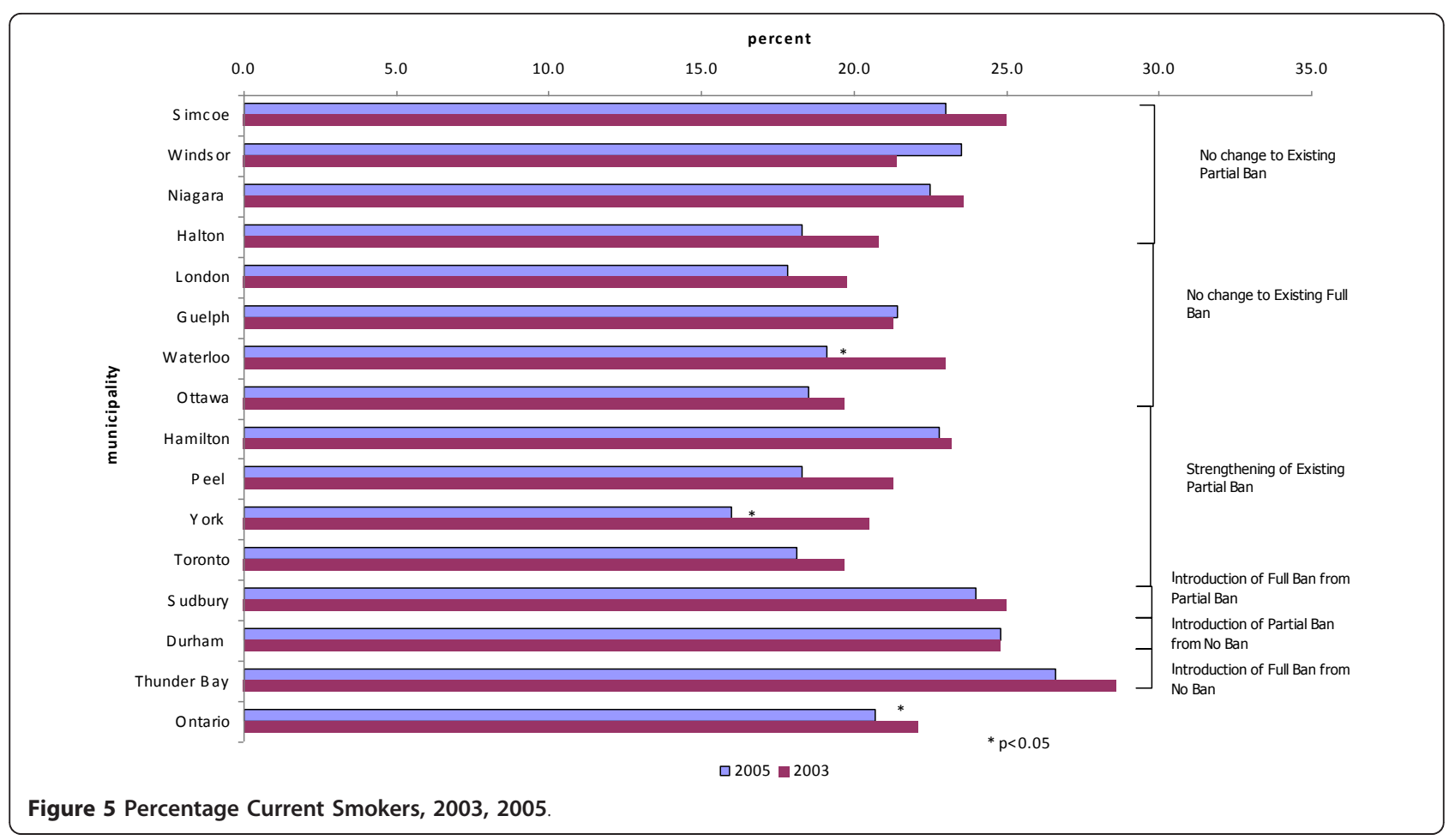

could have a significant impact on vulnerable populations. The main exposure for children occurs at home [20] and it has been established that SHS in homes can reach levels seen in bars [21]. SHS in vehicles is considered to be even more hazardous because of the smallenclosed space [22]. We found that exposures in both vehicles and at home decreased following the introduction of bans. These results are consistent with the results of a cross-sectional survey in Scotland, which found no increase in secondhand exposure among children after the implementation of a smoking ban [14].

Although a causal relationship cannot be proven with ecological observational data, the application of the Bradford-Hill criteria can be applied in support [23]. First, the introduction of anti-smoking legislation was followed by declines in exposures in multiples environments across all municipalities. These results meet the consistency criterion. Second, a dose-response is seen in that municipalities with full bans had larger reported declines in SHS than partial ban locations and municipalities with no bans had the smallest declines. Third, temporality can be observed in areas in which municipalities introduced anti-smoking legislation at a later time had both higher rates of active smokers and SHS exposures and lower rates of workplace restriction. Municipalities with the earliest introduction of full smoking bans had the lowest rates of SHS exposure in a public place. Fourth, the association between anti-smoking legislation and exposure is coherent with our current understanding and the results are theoretically plausible as one would expect a decline in exposures after the implementation of a measure designed to lower exposure. We are, however, unable to meet the criteria for specificity as other variables may have influenced our results such as increased cigarette taxation.

There are some limitations to consider. Previous studies have faced methodological criticisms including the lack of individual patient-level information such as exposure to passive smoking. Ideally, a study concerned with the impact of SHS should assess individual SHS exposure. One should show that exposures to SHS have decreased following the introduction of smoking bans. To assess exposure we used two iterations of a large Canadian survey of SHS exposure in multiple environments. Using a well-validated population survey data provided us with a timely estimate of exposures over a four-year period. However, survey results were selfreported and consequently respondents may have given answers considered socially acceptable but that did not reflect actual behaviour. Questions were also limited to the population over age 12 and thus do not reflect children's smoking exposures, a population at greater physiological risk of SHS. However, it could be argued that rates of SHS exposure in vehicles and at home provide a good estimate of children's exposure. Finally, this study could only use questions from the 2003 and 2005 survey as the 2000-2001 survey contained one question about SHS exposure. This question is not directly comparable 
with questions in subsequent surveys. Exposure rates from all three years would have allowed relationships between smoking bans and exposures to be better delineated and trends to be determined. Between 2003 and 2005, only three municipalities (Sudbury, Durham, and Thunder Bay) had major changes to smoking regulations. These municipalities had large changes in exposure rates. For other municipalities, it is harder to determine the late effects of the introduction of antismoking legislation from underlying trends. Our results may overestimate the impact of anti-smoking legislation, as there has been a decreasing trend in exposure to passive smoking and the prevalence of smokers in most industrialized countries prior to the introduction of anti-smoking by-laws. Nevertheless, other research has shown a significant reduction in hospital admissions following the introduction of these laws [24].

\section{Conclusions}

In summary, this study shows that smoking bans appear to play an important role in decreasing exposure to SHS and appear to be effective in decreasing exposure in workplaces and public places. Unfortunately, this study highlights that SHS is still occurring in environments legislated to be smoke-free. The large variation among areas illustrates that smoking bans are necessary but alone are insufficient to completely eliminate exposure. Our study helps establish the relationship between the implementation of public smoking bans and exposure rates and smoking prevalence. In addition to decreasing exposure in public places as would be expected from anti-smoking legislation, bans also appear to have additional benefits by decreasing rates of current smokers and decreasing exposures to SHS in private settings. Consequently, the introduction of bans may help publicize the health impact of active and passive smoking on health and discourage smoking by restricting locations in which one can smoke. In this way, smoking bans may be another valuable tool available for encouraging individuals to stop smoking as well as providing a legislative means to decrease exposure to SHS in both private and public settings. Smoking bans and other smoke-free strategies could have immense public impact as it is estimated that one billion people are expected to die during the $21^{\text {st }}$ century as a result of tobacco-related disease [25].

\section{Additional material}

Additional file 1: CCHS survey questions pertaining to secondhand smoke and smoking status. Survey questions from the 2.1 and 3.1 versions of the CCHS that relate to secondhand exposure in different settings and current smoking status.

\section{Author details}

${ }^{1}$ Primary Care and Population Health, Institute for Clinical and Evaluative Studies, (2075 Bayview Avenue Room G1-06), Toronto, (M4N 3M5), Canada. ${ }^{2}$ Department of Community and Family Medicine, University of Toronto,(263 McCaul Street, 5th Floor) Toronto, (M5T 1W7), Canada. ${ }^{3}$ Department of Family Medicine, Toronto East General Hospital, (825 Coxwell Avenue, Room B-112), Toronto, (M4C 3E7), Canada. ${ }^{4}$ Department of Family Medicine, St. Michael's Hospital, (30 Bond Street), Toronto, (M5B 1W8), Canada. ${ }^{5}$ Dalla Lana School of Public Health, University of Toronto, (155 College Street, Health Science Building, 6th Floor), Toronto (M5T 3M7), Canada.

\section{Contributors}

AN was involved in the acquisition of the data, wrote the initial draft of the manuscript, and is guarantor. RG was involved in the study supervision. RM conducted the statistical analyses. All authors contributed to the design of the study, interpretation of the data and critical revision of the manuscript. All authors read and approved the final manuscript.

\section{Funding/Support}

Department of Family and Community Medicine, University of Toronto, Toronto East General Hospital, Toronto, Ontario

\section{Competing interests}

The authors declare that they have no competing interests.

Received: 2 September 2010 Accepted: 3 March 2011

Published: 3 March 2011

\section{References}

1. Nelson E: The Miseries of passive smoking. Human and Experimental Toxicology 2001, 20:61-83.

2. World Health Organization. Tobacco Free Initiative. Frequently asked questions about second hand smoke. [http://www.who.int/tobacco/ research/secondhand_smoke/faq/en/index.html].

3. Perez CE: Second-hand smoke exposure - who is at risk? Health Reports 2004, 16:9-18.

4. Fong GT, Hyland A, Borland R, et al: Reductions in tobacco smoke pollution and increases in support for smoke-free public places following the implementation of comprehensive smoke-free workplace legislation in Ireland: Findings from the ITC Ireland/UK Survey. Tobacco Control 2004, 15(suppl III):11151-iii-58.

5. Ontario. [http://en.wikipedia.org/wiki/Ontario_Canada].

6. Statistics Canada, Population and dwelling counts, for Canada, provinces and territories, and census subdivisions (municipalities), 2006 and 2001 censuses - 100\% data. [http://www12.statcan.ca/english/census06/data/ popdwell/Table.cfm? $T=302 \& S R=1 \& S=3 \& O=D \& R P P=25 \& P R=35]$.

7. Smoking Bans, Canadian Municipal By-laws Banning Smoking in Public Places, Health Canada. [http://www.statcan.gc.ca/pub/82-003-x/2006008/ article/smoking-tabac/t/4060721-eng.htm].

8. Ontario Municipal Home Pages. [http://www.amo.on.ca/YLG/ylg/ontario.html].

9. Smoking - prevalence, bans and exposure to Second hand smoke. [http://www.tbs-sct.gc.ca/dpr-rmr/2006-2007/inst/stc/stc-eng.pdf].

10. Statistics Canada, Health Region Profiles. [http://www.statcan.gc.ca/cgibin/imdb/p2SV.pl? Function=getSurvey \&SDDS=3226\&lang $=e n \& \mathrm{db}=\mathrm{imdb} \& \mathrm{adm}=8 \& \mathrm{dis}=2]$.

11. CANISM - Pick Lists Table 105-0400: [http://cansim2.statcan.gc.ca/cgi-win/ CNSMCGI.EXE?\&Lang=E\&Arrayld=105-0400\&Array_Pick=1\&Det], Canadian Community Health Survey (CCHS 2.1 and 3.1) Indicator profile, by sex, Canada provinces, territories, health regions (June 2005 boundaries) and peer groups, every 2 years (173576) Statistics Canada.

12. Carriere $\mathrm{KC}$, Roos LL: Comparing standardized rates of events. American Journal of Epidemiology 1994, 140:472-482.

13. Haw SJ, Gruer L: Changes in adult exposure to second-hand smoke following the implementation of smoke-free legislation. BMJ 2007, 335:549-52.

14. Akhtar PC, Currie DB, Currie CE, et al: Changes in child exposure to environmental tobacco smoke (CHETS) study after implementation of smoke-free legislation in Scotland: national cross sectional survey. BMJ 2007, 335:545 
15. Survey on Tobacco Analytical Report. Flash Eurobarometer European Commission. [http://ec.europa.eu/health/ph_determinants/life_style/ Tobacco/Documents/eb_253_en.pdf].

16. CDC: State-Specific Secondhand Smoke Exposure and Current Smoking Among Adults - United States,2008. MMWR 2009, 58:1232-1235 [http:// www.cdc.gov/mmwr/preview/mmwrhtml/mm5844a3.htm].

17. Fichtenberg CM, Glantz SA: Effect of smoke free workplaces on smoking behaviour: systematic review. BMJ 2002, 325:188-91.

18. Gallus $\mathrm{S}$, Zuccaro $\mathrm{P}$, Colombo $\mathrm{P}$, et al: Effects of new smoking regulations in Italy. Ann Oncol 2006, 17:346-347.

19. Allwright $\mathrm{S}$, Paul $\mathrm{G}$, Greiner B, et al: Legislation for smoke-free workplaces and health of bar workers in Ireland: before and after study. BMJ 2005, 331:1117-1120

20. Jakkoka MS, Jaakkoka JJK: Impact of smoke-free workplace legislation on exposures and health: possibilities for prevention. European Respiratory Journal 2006, 28:397-408.

21. Reace Jl: Risk management of passive smoking at work and at home. Saint Louis University Public Law Review 1994, 13:763-785.

22. Ott W, Langan L, Switzer P: A time series model for cigarette smoking activity patterns: model validation for carbon monoxide and respirable particles in a chamber and an automobile. J Expo Anal Environ Epidemiol 1992, 2:175-200

23. Hill AB: The environment and disease: Association or causation Proceedings of the Royal Society of Medicine 1965, 58:295-300.

24. Naiman A, Glazier RH, Moineddin R: Association of anti-smoking legislation with rates of hospital admission for cardiovascular and respiratory conditions. CMAJ 2010, 182:761-7.

25. Teo K, Ounpuu S, Hawken S, et al: Tobacco use and risk of myocardial infarction in 52 countries in the INTERHEART study: a case control study. The Lancet 2006, 368:647-658.

\section{Pre-publication history}

The pre-publication history for this paper can be accessed here: http://www.biomedcentral.com/1471-2458/11/146/prepub

doi:10.1186/1471-2458-11-146

Cite this article as: Naiman et al:: Is there an impact of public smoking bans on self-reported smoking status and exposure to secondhand smoke? BMC Public Health 2011 11:146.

\section{Submit your next manuscript to BioMed Central and take full advantage of:}

- Convenient online submission

- Thorough peer review

- No space constraints or color figure charges

- Immediate publication on acceptance

- Inclusion in PubMed, CAS, Scopus and Google Scholar

- Research which is freely available for redistribution 